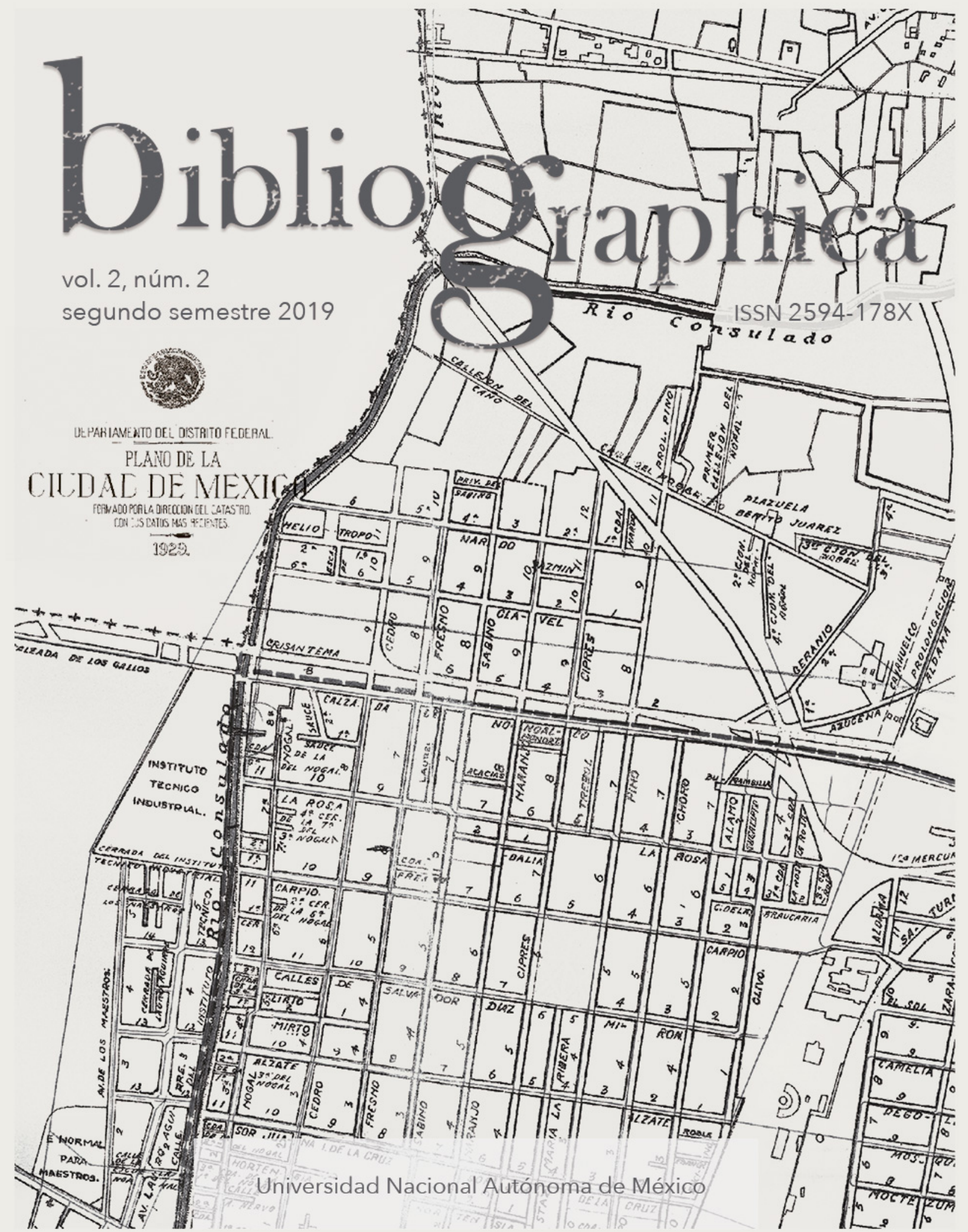




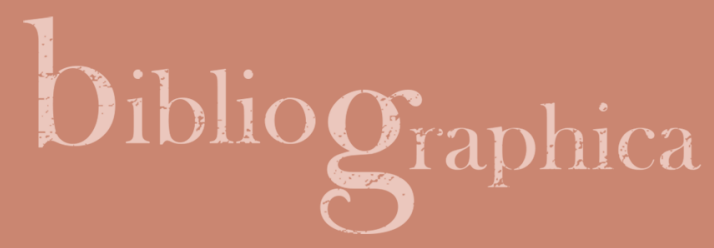

\section{La Mapoteca de la Biblioteca Nacional} de México: una aproximación a su estudio

The Cartographic Collection of the National Library of Mexico: An Approach to its Study

\section{Ramona I. Pérez Bertruy}

ramonap@unam.mx

\section{Rocío Cázares Aguilar}

rocio@unam.mx

\section{Alejandra Odor Chávez}

alejandraoc@unam.mx

Universidad Nacional Autónoma de México

Instituto de Investigaciones Bibliográficas

Recepción: 26.04.2019 / Aceptación: 28.08.2019

DOI: https://doi.org/10.22201/iib.bibliographica.2019.2.53 
Resumen Estudio sobre las colecciones de la Mapoteca de la Biblioteca Nacional de México (BNM), con base en la organización documental de su acervo a través del tiempo, para señalar los avances de su catalogación y el estado de conservación de los materiales. Por igual, interesa dar a conocer los tipos de documentos que resguarda y evaluar la importancia que tienen esta cartografía y sus impresos como potencial para los diversos saberes científicos, sociales y humanísticos de la nación. Se reflexiona acerca del reto y el gran quehacer pendiente en materia de catalogación, así como sobre la tarea imperiosa de trabajar con los Departamentos de Conservación, Restauración, Preservación y Reprografía de la BNM, para estabilizar y garantizar el acceso a este acervo.

Palabras clave

Abstract

Mapoteca; Biblioteca Nacional de México; colecciones; valor documental; conservación y preservación.

Study on the Cartographic Collection of the National Library of Mexico (known by its initials in Spanish as BNM), based on its documental organization through time, to assess its cataloging progress and the conservation conditions of the materials. What matters here is to equally disseminate the types of documents that constitute the collection and to ponder the importance of this cartography and its printed materials as potential sources for the scientific, social and humanistic knowledge of the nation. It also reflects on the challenges and the great remaining task in terms of cataloging, just as the imperative need of working with the BNM's Conservation, Restoration, Preservation and Digital Reprography departments in order to stabilize and guarantee the access to this collection.

Keywords Cartographic collection; National Library of Mexico; collections; documentary value; conservation and preservation. 


\section{Introducción}

En 1979 fue inaugurado el nuevo edificio de la Biblioteca y Hemeroteca Nacionales en el Centro Cultural Universitario de la Universidad Nacional Autónoma de México (UNAM). A partir de entonces comenzó el traslado de los acervos documentales desde la antigua iglesia de San Agustín hacia el nuevo recinto. El proyecto arquitectónico consideró pequeñas salas para albergar materiales que fueron separados de la colección general porque su naturaleza y formato exigían un tratamiento especial, entre ellos material gráfico y didáctico, partituras, libros en braille, películas, casetes, atlas y mapas.

La bibliotecóloga Gloria Escamilla fue la artífice de las llamadas "salas especiales", entre ellas la de Mapoteca, que comenzó a organizarse como tal a partir de 1980. Ludmilla Valadez Valderrábano comenta cómo se iniciaron las labores en aquel entonces:

Las guías y los atlas ya se encontraban clasificados y fueron colocados en la estantería, sin embargo, los mapas se comenzaron a catalogar porque no habían sido trabajados, e inclusive no había planeros suficientes para guardarlos. La maestra Gloria Escamilla y yo visitamos varias mapotecas, entre ellas la Manuel Orozco y Berra, y fue a partir de esas visitas que se adquirieron los maperos adecuados para el material cartográfico.'

A partir de ese momento comenzó a conformarse la colección de la Mapoteca, tomando como base atlas, libros especializados en geografía de México y del mundo, guías turísticas y de carreteras, al igual que mapas y planos. Durante más de dos años se estuvieron adecuando las nuevas instalaciones, hasta que finalmente el 12 de abril de 1982 se empezó a dar servicio a los usuarios. ${ }^{2}$

Para enriquecer la colección de mapas de México solicitaron al Instituto Nacional de Estadística, Geografía e Informática (INEGI) la donación de sus publicaciones vía Depósito Legal, que se efectuó con cierta regularidad a partir de 1983. Cuando las instalaciones de esa institución resultaron afectadas por

\footnotetext{
${ }^{1}$ Rocío Cázares Aguilar, Entrevista a Ludmilla Valadez Valderrábano, el 10 de octubre de 2018.

${ }^{2}$ Aurora Serrano y Ludmilla Valadez, "Los servicios al público en las salas de bibliografía y mapoteca de la Biblioteca Nacional de México", en Hacia un servicio bibliotecario nacional: memorias de la VII Semana de Bibliotecología, del 8 al 10 de febrero de 1984 (Guadalajara: UAG, División de Educación Continua, Dirección de Bibliotecas Médicas, Facultad de Filosofía y Letras, Escuela de Bibliotecología, 1984), 102.
} 
el sismo de 1985, el repositorio de la Mapoteca sirvió como fuente de consulta para los distintos usuarios del INEGI que buscaban información topográfica, hidrológica y sobre límites geográficos, entre otros temas. El INEGI depositó a su vez los anuarios, censos y estadísticas oficiales de todos los estados de la república mexicana. ${ }^{3}$

Si revisamos las fuentes históricas, podemos encontrar información sobre la colección "de origen" de la Mapoteca. El catálogo de José María Vigil (en su novena división, de historia y ciencias auxiliares, fechado en 1893) enlista 84 atlas y 24 cartas o mapas. ${ }^{4}$

En Historia de la Biblioteca Nacional de México, de 1948, Rafael Carrasco Puente ofrece cifras de los documentos existentes entre 1910 y 1940, para hacer un análisis comparativo del estado de la institución y sus volúmenes en el año de la Revolución y 30 años después. Asevera que los mapas y planos en 1910 eran 623, y en 1940 el acervo constaba de 1152 ejemplares. ${ }^{5}$

Juan B. Iguíniz -en su descripción de la Biblioteca Nacional de México en 1940- menciona que las fuentes de adquisición de libros han sido el Depósito Legal, la propiedad literaria, el canje de obras y la partida presupuestal de la propia biblioteca. ${ }^{6}$ En su lista de las principales colecciones, destaca la de cartografía e iconografía: "La sección de mapas, planos, grabados, estampas, fotografías, etc., es de reciente creación, y se ha formado con ejemplares ya existentes en la Biblioteca a los que se han agregado otros adquiridos por compras o donaciones". ${ }^{7}$

Apunta Iguíniz que dentro de los catálogos de la Biblioteca se cuenta con el cartográfico, pero desafortunadamente no hay un listado de las existencias de aquel entonces. ${ }^{8}$ Por su parte, Aurora Serrano y Ludmila Valadez informan que la colección rondaba los tres mil mapas al momento de trasladarse de San Agustín a la UNAM, es decir, en 1980: "aunque la Sala de Mapoteca se organiza en las nuevas instalaciones, ya contaba en su antiguo edificio con un pequeño acervo de

\footnotetext{
${ }^{3}$ Cázares Aguilar, Entrevista...

${ }^{4}$ José María Vigil, Catálogos de la Biblioteca Nacional de México; novena división, historia y ciencias auxiliares (México: Secretaría de Fomento, 1893), 19-23.

${ }^{5}$ Rafael Carrasco Puente, Historia de la Biblioteca Nacional de México, con texto en inglés traducido por Erwin K. Mapes (México: Secretaría de Relaciones Exteriores, Departamento de Información para el Extranjero, 1948).

" Juan B. Iguíniz, "La Biblioteca Nacional de México", Revista de Historia de América 8 (abril de 1940): 73.

7 Ibid., 76.

8 Ibid., 80.
} 
3000 mapas guardados en dos planeros, pero como es de suponer, el servicio que se prestaba era muy irregular y esporádico"9 (Cuadro 1).

Cuadro 1. Cifras del material cartográfico en diferentes fuentes.

\begin{tabular}{cccc}
\hline Año citado & Fuente & Atlas & Cartas/Mapas \\
\hline $\mathbf{1 8 9 3}$ & José María Vigil & 84 & 24 \\
$\mathbf{1 9 1 0}$ & Rafael Carrasco Puente & 623 \\
$\mathbf{1 9 4 0}$ & Rafael Carrasco Puente & 1,152 \\
$\mathbf{1 9 8 0}$ & $\begin{array}{c}\text { Aurora Serrano, } \\
\text { Ludmilla Valadez }\end{array}$ & 3,000 \\
\hline
\end{tabular}

Las autoras exponen que hacia 1984 la mapoteca tenía 12500 mapas, 250 atlas y 650 monografías de consulta en geografía, ${ }^{10}$ por lo que su crecimiento fue exponencial, en parte gracias al depósito de materiales que realizó el INEGI, como se mencionó (Cuadro 2).

Cuadro 2. Cifras comparativas entre 1984 y 2018.

\begin{tabular}{ccccccc}
\hline Año & Fuente & Atlas & Mapas & Monografias & $\begin{array}{c}\text { Publicaciones } \\
\text { Periódicas }\end{array}$ & $\begin{array}{c}\text { Mapas } \\
\text { Murales }\end{array}$ \\
\hline $\mathbf{1 9 8 4}$ & $\begin{array}{c}\text { Serrano y } \\
\text { Valadez }\end{array}$ & 250 & 12,500 & 650 & & \\
$\mathbf{2 0 1 8}$ & Sifib & 883 & 6,500 & 16,192 & 743 & 21 \\
\hline
\end{tabular}

De acuerdo con el Sistema de Inventario Físico para Bibliotecas (Sifib), en la actualidad hay en la Mapoteca 883 atlas, 16192 monografías, 743 publicaciones periódicas, 21 mapas murales y 6500 mapas o planos. La diferencia en las cifras de mapas entre 1984 y 2018 da cuenta del material que falta por catalogar, más el que ha ingresado durante ese periodo. Por ello se calcula que el número de mapas asciende a 18 mil ejemplares, aproximadamente, es decir que sólo está inventariada y catalogada una tercera parte de la colección (Cuadro 3). Hasta aquí el intento por reconstruir en cifras y periodos la formación de las colecciones de la Mapoteca.

\footnotetext{
9 Serrano y Valadez, "Los servicios al público...", 99.

10 lbid., 102.
} 
Cuadro 3. Cifras aproximadas del material cartográfico en 2018.

\begin{tabular}{lcc}
\hline Año & Fuente & Mapas \\
\hline $\mathbf{2 0 1 8}$ & Conteo físico & 18,000 \\
\hline
\end{tabular}

A partir de la aparición del nuevo estándar de catalogación denominado Recurso, Descripción y Acceso (RDA), los materiales cartográficos pueden ser descritos con mayor amplitud en sus características físicas y es posible especificar las funciones de los diferentes autores que intervienen en su creación. Este paradigma promete interrelacionar información de diferentes recursos, ahora llamados "entidades", a través de los metadatos asignados, para que el usuario pueda acceder a ellos fácilmente. La tarea del catalogador seguirá siendo crucial para ofrecer los mejores y más precisos puntos de acceso en la descripción de los atlas y mapas.

En la BNM comenzó a implementarse el RDA a partir del año 2015, para lo cual se hicieron ajustes en el registro de la ficha de las entidades. El reto del descriptor o "metacatalogador" de estos materiales no difiere en mucho del que tiene cualquier otro tipo documental, pues deberá analizar el todo y sus partes esquemáticamente, asignar autoridades adecuadas y suficientes, además de proporcionar la información más relevante al usuario final. Es necesario, por tanto, seguir avanzando en el registro descriptivo de las obras y sus creadores, para dar a conocer y proteger, a su vez, el patrimonio cartográfico nacional.

Ahora bien, la tarea de catalogación no es el único reto que se tiene enfrente, pues los mapas, cartas y atlas en sus múltiples tamaños y formatos presentan necesidades especiales de conservación. ${ }^{11}$ Al respecto, se cuenta con el apoyo del Departamento de Conservación y Restauración de la Biblioteca Nacional, al igual que del Departamento de Reprografía y Preservación Digital de la Hemeroteca Nacional (antes Unidad de Microfilmación y Fotografía) que, a través del trabajo en colaboración, han implementado proyectos para estabilizar y digitalizar el material que se ha solicitado atender.

\footnotetext{
${ }^{11}$ Gloria Escamilla, "Consideraciones sobre la organización de los materiales cartográficos", Boletín del Instituto de Investigaciones Bibliográficas, núms. 14-15 (1977-1978): 589.
} 


\section{Los retos para la preservación}

La preservación de colecciones especiales -específicamente de grandes formatos, como es el caso de la Mapoteca de la BNM- representa necesidades y retos particulares en cuanto a su almacenamiento, diagnóstico, estabilización y conservación, e implica el trabajo colaborativo y corresponsable entre diversas áreas de la institución. ${ }^{12}$

La Mapoteca es una de las siete salas especiales con las que cuenta la Biblioteca Nacional de México y, junto con las colecciones que conforman sus Fondos Reservado y Contemporáneo, constituye el gran corpus documental que el Departamento de Conservación y Restauración tiene como misión atender. Por tal motivo, el cuidado y la toma de decisiones en cuanto a la conservación del material cartográfico deben ser valorados y llevados a cabo considerando las prioridades tanto de ésta como del resto de las colecciones de ambos fondos. Lo anterior significa que, si bien todos los documentos cartográficos tienen necesidades importantes en materia de conservación, es posible que se presenten casos que requieran atención prioritaria o simultánea en otros conjuntos documentales, lo cual implica que los recursos, el tiempo y los materiales destinados a cada acervo sean administrados de forma paulatina, pero constante, mediante el desarrollo de diversos proyectos y programas.

La principal estrategia para lograr una verdadera corresponsabilidad y objetividad en la toma de decisiones en cuanto a la conservación de las colecciones de la BNM ha sido la conformación de un Comité de Conservación, Encuadernación y Restauración donde participan las diferentes jefaturas de departamento de la institución, así como la Coordinación de la misma y la Secretaría Administrativa. Este órgano consultivo funciona desde el año 2010, y garantiza que las necesidades de todas las áreas sean consideradas y evaluadas a fin de generar los proyectos y programas más adecuados para cada momento y situación, así como para asegurar su seguimiento y mejora continua.

\footnotetext{
12 Preservación son las "acciones y consideraciones administrativas, financieras y de conservación, incluyendo estipulaciones sobre políticas, recursos humanos, instalaciones, almacenamiento, técnicas y métodos tendientes a garantizar la permanencia física de los acervos documentales y la información contenida en ellos. La preservación, entendida de esta manera, constituye la gestión de la conservación de dichos acervos". Subcomité de Normalización para la Preservación de Acervos Documentales del Cotenndoc, "NMX-R100-SCFI-2018, Acervos Documentales-Lineamientos para su preservación", declaratoria de vigencia en proceso de publicación.
} 
Durante los últimos años, y a partir de lo acordado en el Comité mencionado, se han implementado diversas estrategias de preservación para las colecciones de la Mapoteca que van desde lo general-por ejemplo el reacomodo, la limpieza y las adecuaciones arquitectónicas en el depósito que la resguarda- a lo más particular, como la estabilización y digitalización de aquellos materiales considerados prioritarios o que han sido solicitados por diversos usuarios.

Puesto que se trata de un acervo con una diversidad importante de formatos (libros, revistas, atlas y mapas de grandes dimensiones), el almacenamiento del material cartográfico puede implicar dificultades que no son comunes en otro tipo de acervos, y que fácilmente pueden derivar en su deterioro, así como en la falta de espacio suficiente para el adecuado acomodo de los documentos. Debido a lo anterior, una de las principales líneas de acción en materia de conservación, llevada a cabo desde principios del año 2017, ha sido el favorecer la limpieza y el orden físico de las colecciones, con la finalidad de optimizar el espacio de almacenamiento, reducir los riesgos de deterioro de los documentos y definir con mayor facilidad las necesidades más específicas de catalogación, reubicación, estabilización, etcétera.

Una de las primeras tareas fue colocar, al igual que en el resto de los depósitos con ventanales en la fachada norte del cuarto, tercer y segundo pisos del edificio, un muro de tablaroca con aislante térmico, a fin de evitar la entrada de luz natural a través del ventanal, puesto que la radiación ultravioleta e infrarroja contribuyen a la degradación de los materiales orgánicos y a las variaciones en las condiciones ambientales al interior de los depósitos. Posteriormente se llevó a cabo la reubicación de 18 planeros y 86 estantes dobles, para aprovechar mejor el espacio del depósito, y se adecuó un estante doble con las charolas colocadas de tal manera que permitan el almacenamiento adecuado (en horizontal) de los atlas de gran formato, que antes no contaban con espacio suficiente.

Como medida primordial de conservación para cualquier acervo documental, debe considerarse la limpieza de los espacios y las colecciones, ya que la acumulación de polvo puede promover diversos deterioros: manchas, abrasión o desarrollo de microorganismos como hongos y bacterias. Recientemente se hizo la limpieza profunda del depósito de la Mapoteca, y el material que aún estaba suelto fue guardado en cajas de polipropileno para brindarle mayor protección mientras es posible procesarlo adecuadamente. ${ }^{13}$

${ }^{13}$ Esta limpieza incluyó aspirado de techos, paredes, ductos, lámparas, pisos y estantes, además de los documentos mismos. 
A la par de estas acciones, personal del Departamento de Conservación y Restauración de la BNM ha atendido aquellos materiales con deterioros muy avanzados que requerían de una intervención para poder ser consultados o digitalizados. Cabe destacar la estabilización de una parte de la colección Guía Roji, en la que se trabajaron 9 de los ejemplares más antiguos (Imagen 1).

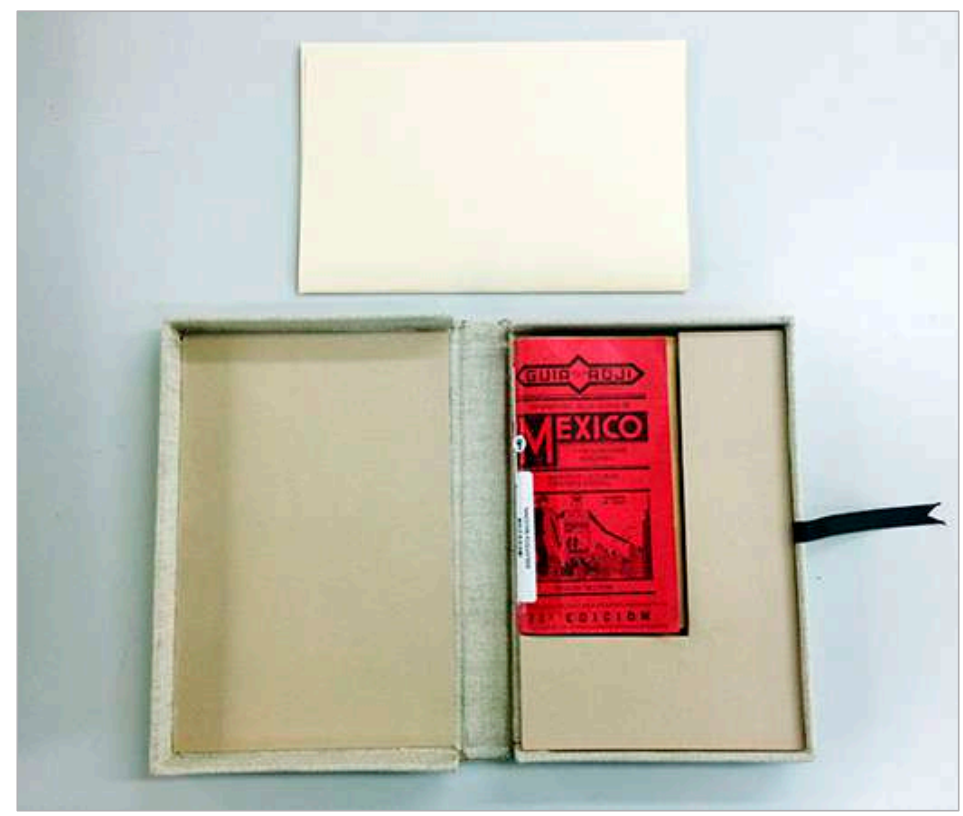

Imagen 1. Ejemplar de la colección de Guía Roji después de la intervención de estabilización.

Del mismo modo, se han estabilizado distintos mapas de gran formato, especialmente de la Ciudad de México por ser los más consultados. Otra característica del trabajo realizado durante los últimos años, encaminado hacia la conservación a largo plazo de los materiales estabilizados, ha sido su digitalización, llevada a cabo por personal del Departamento de Preservación y Reprografía de la Hemeroteca Nacional de México. La reproducción digital de los mapas, especialmente los de gran formato, favorece su consulta y conservación al reducir la necesidad de manipularlos constantemente para su uso. Incluso la impresión de algunas de estas reproducciones digitales ha favorecido su consulta en sala, sin necesidad de manipular los originales ya estabilizados. 
Uno de los principales retos para la conservación del material cartográfico de la BNM consiste en el almacenamiento adecuado de los materiales, pues el espacio físico en el cual se ubica presenta saturación, tanto del mobiliario como de los documentos que resguarda. Asimismo, el gran formato de algunos documentos ha propiciado que se almacenen enrollados, lo cual no es la forma más recomendable para hacerlo. Aunque es aconsejable almacenar los mapas de forma desplegada y en plano, ${ }^{14}$ en casos donde el espacio es una limitante pueden explorarse otras opciones, como ciertas técnicas de enrollado de los documentos cuyo soporte aún presenta flexibilidad suficiente. ${ }^{15}$ Ésta es una práctica común en la Mapoteca de la BNM, donde se ha buscado dotar a los mapas con un soporte rígido sobre el cual son enrollados y posteriormente se envuelven con materiales adecuados para su conservación a largo plazo. Otra gran parte del acervo aún requiere guardas de primer nivel con el propósito de brindar mayor protección a los documentos, lo que deberá ser considerado y atendido conforme lleguen los recursos necesarios, dentro de los proyectos establecidos institucionalmente.

Por otro lado, es indispensable conocer y aplicar las mejores prácticas para el uso y la manipulación de los mapas y planos, especialmente aquellos de formatos mayores cuyo manejo requiere a más de una persona. La manipulación inadecuada de los mapas puede ser uno de los principales factores que influya en su deterioro, que en todos los casos son fácilmente prevenibles, por lo cual es necesario que el personal que los manipule cuente con la capacitación adecuada para hacerlo, y que transmita a los usuarios los lineamientos básicos para su correcto uso.

La participación activa del personal bibliotecario en la adecuada manipulación y almacenamiento de los documentos es un factor fundamental para su conservación, pues es quien se encuentra con mayor frecuencia en contacto directo con éstos, razón por la cual el Departamento de Conservación y Restauración ha trabajado en constante colaboración con la responsable y los bibliotecarios de la Mapoteca, brindando las asesorías solicitadas sobre deterioros detectados, las mejores prácticas para su almacenamiento y uso, la elaboración de guardas de primer nivel, e incluso para la estabilización de deterioros

\footnotetext{
${ }^{14}$ Kathleen Weessies, "Care of Rare Map Collections in the Twenty-First Century", Journal of Map \& Geography Libraries 10, núm. 2 (julio de 2014): 204-235. Rocío Hermosín Miranda, "Características de los distintos soportes sobre los que se reproducen planos y esferas", Revista ph 77 (febrero de 2011): 52.

15 Weessies, "Care of Rare Map Collections...", 218.
} 
puntuales que no requieren de una intervención mayor, pero sí aseguran que los daños no continúen o no generen pérdida de información.

Los retos para la preservación de los documentos cartográficos de la BNM son diversos, y sin duda requerirán del trabajo persistente en conjunto de distintos especialistas relacionados con su adquisición, catalogación, inventario, conservación, investigación y difusión. Debido a la especialización que implica no sólo el estudio y la difusión, sino el procesamiento y la conservación de las colecciones cartográficas, es preciso contar con el permanente compromiso institucional para determinar y solventar sus necesidades, a fin de mantener estas colecciones accesibles y en constante uso y circulación.

\section{Valor documental}

A continuación presentamos una reseña sobre el valor documental que tienen las colecciones más importantes que alberga la Mapoteca, tomando en cuenta que posee un amplio acervo bibliográfico y hemerográfico, compuesto fundamentalmente por materiales del siglo XX y con poca documentación correspondiente a los siglos XIX y XVIII.

$85 \%$ del acervo corresponde al depositado principalmente por el INEG| ${ }^{16}$ a partir de 1983, cuando precisamente se crea ese instituto. La Mapoteca resguarda de esta institución una enorme cantidad de cartografía suelta conformada por cartas topográficas, hidrológicas, ${ }^{17}$ edafológicas, ${ }^{18}$ de efectos climáticos y

${ }^{16}$ El INEGI se creó por decreto presidencial el 25 de enero de 1983 y aglutinó a diversos organismos que le precedieron: a la Dirección General de Estadística en funciones, desde 1882; a la Dirección General de Geografía, establecida en 1968 y adscrita a la Secretaría de la Presidencia; a la Dirección General de Política Informática y a la Dirección General de Integración y Análisis de la Información. Con su formación, el INEGI modernizó la valiosa tradición que tenía nuestro país en materia de captación, procesamiento y difusión de la información estadística y geográfica. En el año 2008 obtuvo su autonomía como organismo público descentralizado, al entrar en vigor el 16 de abril de ese año la ley del Sistema Nacional de Información Estadística y Geografía. INEGI, "Institución con historia", acceso el 17 de mayo de 2019, https://www.inegi.org.mx/inegi/quienes_somos.html, e "Instituto autónomo, de frente a los nuevos retos", acceso el 17 de mayo de 2019, https://www.inegi. org.mx/inegi/quienes_somos.html.

17 Mapas que representan los principales rasgos físicos naturales y culturales de nuestro país, por ejemplo la orografía, hidrografía, vegetación densa y las poblaciones con su correspondiente toponimia y límites, las actividades educativas y económicas, las localidades, los medios y vías de comunicación.

${ }^{18}$ Cartografía que refleja las características morfológicas, físicas y químicas de los suelos del territorio nacional. 
de uso de suelo sobre las localidades del territorio nacional (Imagen 2), un excelente material de apoyo para el conocimiento de nuestro entorno geográfico, además de innumerables fotos satelitales que sirven de base para la interpretación y análisis del espacio terrestre.

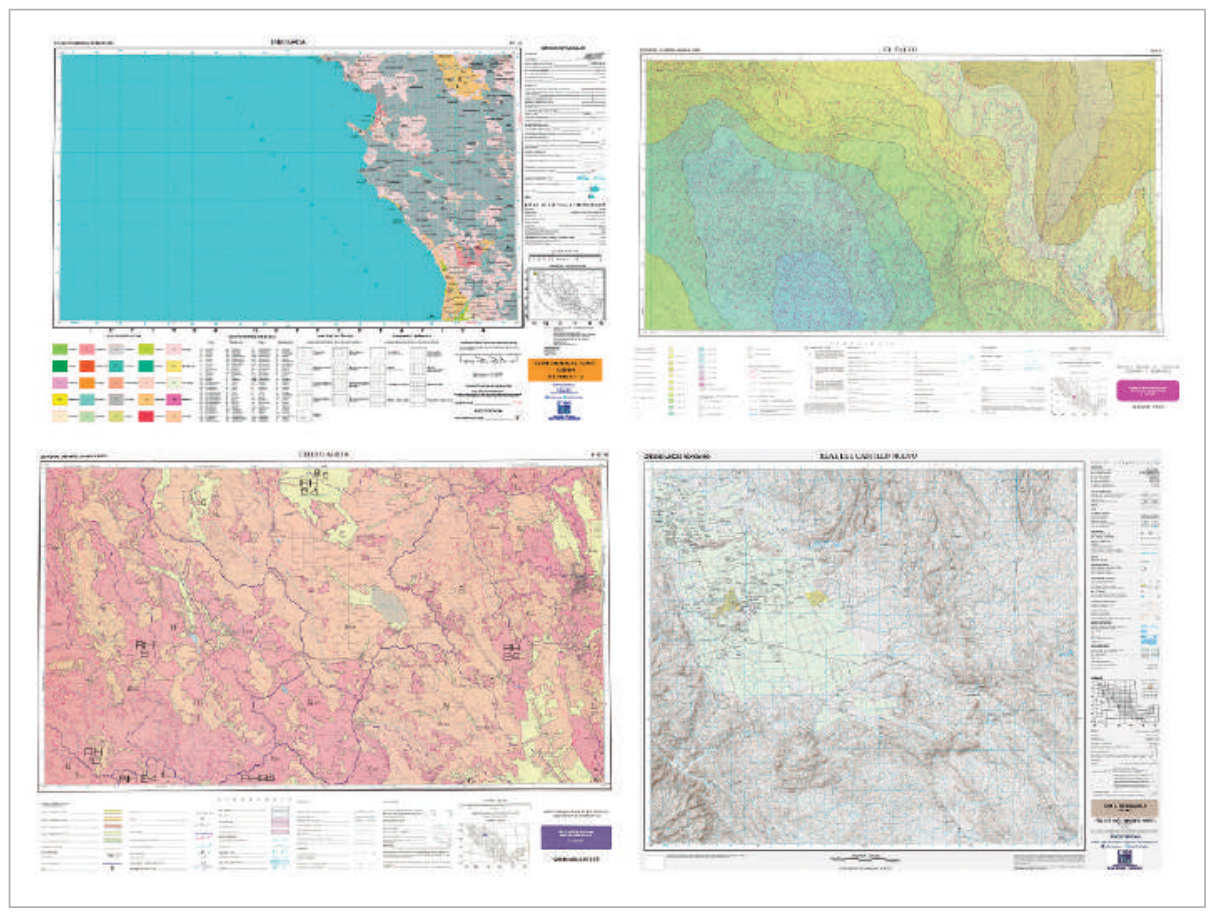

Imagen 2. Cartografía actual del INEGI en la Mapoteca de la BNM.

También pertenecen al acervo obras monográficas y seriadas del INEGI que resultan cruciales para entender el territorio mexicano, los recursos naturales, la población, migración, economía y cultura del país. Destaca en este rubro la Síntesis de Información Geográfica por estados, que pretende dar una visión integrada de la geografía física de cada entidad para el aprovechamiento de sus recursos naturales. Son importantes los censos generales de población, empleo y vivienda, porque registran aspectos demográficos, económicos y sociales estratégicos para la planeación gubernamental. Incluye asimismo los anuarios estadísticos y geográficos por entidades federativas, con indica- 
dores de empleo, salario, urbanización, vivienda, educación, seguridad pública y asistencia social, entre otros. ${ }^{19}$ Se complementa con el Anuario estadístico de los Estados Unidos Mexicanos y la Agenda Estadística de los Estados Unidos Mexicanos, útiles para hacer una comparativa de datos dentro del contexto nacional y con el resto del mundo (Imagen 3).

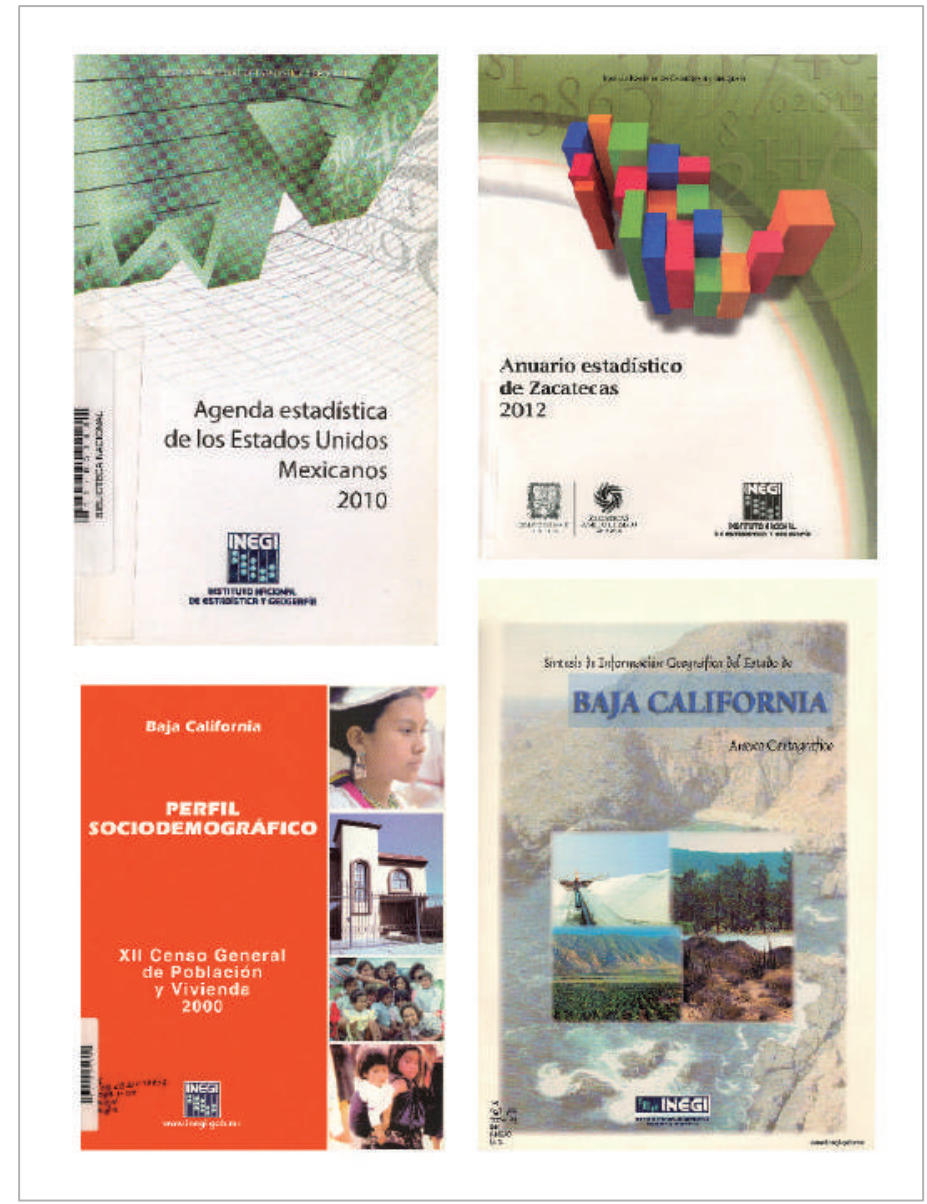

Imagen 3. Obras monográficas y seriadas del INEGI, Mapoteca BNM.

\footnotetext{
${ }^{19}$ INEGI, Perfil Sociodemográfico de Tamaulipas. XII Censo General de Población y Vivienda 2000 (México: INEGI, 2002), IV.
} 
Se suman los Censos económicos por género sobre los sectores manufactureros, de pesca, minería, los industriales y de servicios en México. ${ }^{20}$ Asimismo, aparecen en la estantería de la Mapoteca las encuestas de carácter industrial, con una periodicidad mensual en todo el país. También destaca el Cuaderno de información básica delegacional del Distrito Federal, ${ }^{21}$ que ayuda en la actualización sistemática y oportuna de los distintos aspectos que caracterizan su estructura, mientras que la serie Cuaderno Estadístico Municipal pone el acento en ese nivel de la gestión pública.

Otra colección interesante del INEGI son los cuadernos estadísticos sobre cultura (Imagen 4), donde

se consignan datos relevantes sobre bibliotecas, museos, zonas arqueológicas, monumentos históricos y espectáculos públicos (cinematográficos, teatrales, deportivos, taurinos y recreativos), así como información sobre medios de comunicación impresos y electrónicos, referente a la producción de libros y publicaciones periódicas y a estaciones radiodifusoras y televisoras, ${ }^{22}$

que -en conjunto con las obras periódicas mencionadas- sirven para medir la pobreza, inflación y el crecimiento demográfico, al igual que el acceso a la salud, la educación, las tecnologías y la cultura.

La Mapoteca también conserva del INEGI publicaciones de gran formato colocadas en una estantería especial (Imagen 5), entre ellas el Anuario estadístico del comercio exterior y las publicadas por la Dirección de Estudios del Territorio Nacional, dependiente de la Secretaría de Programación y Presupuesto, sobre la instrumentación de los Sistemas de Cuentas Nacionales de Naciones Unidas, certificada por el Fondo Monetario Internacional. ${ }^{23}$ Por otra parte, son dignos de mención el Atlas de los profesionistas en México ${ }^{24}$-de gran utilidad

20 INEGI, Los hombres y las mujeres en las actividades económicas: censos económicos 2009 (México: INEGI, 2011), VII.

${ }^{21}$ INEGI, Coyoacán: cuaderno de información básica delegacional (México: INEGI, 1989), acceso el 17 de mayo de 2019, https://www.inegi.org.mx/app/biblioteca/ficha.ht$\mathrm{ml}$ ?upc $=702825004885$.

22 INEGI, Estadísticas de cultura (4) (México: INEGI, 2000), acceso el 17 de mayo de 2019, https://www.inegi.org.mx/app/biblioteca/ficha.html?upc=702825465193.

${ }^{23}$ Gabriel Casillas, "Reconocimiento INEGI 2015", El Financiero (29 de septiembre de 2015), acceso el 17 de mayo de 2019, https://www.elfinanciero.com.mx/opinion/gabriel-casillas/ reconocimiento-inegi-2015.

${ }^{24}$ INEGI, Atlas de los profesionistas en México (México: INEGI, 1995), acceso el 17 de mayo de 2019, https://www.inegi.org.mx/app/biblioteca/ficha.html?upc=702825460310. 


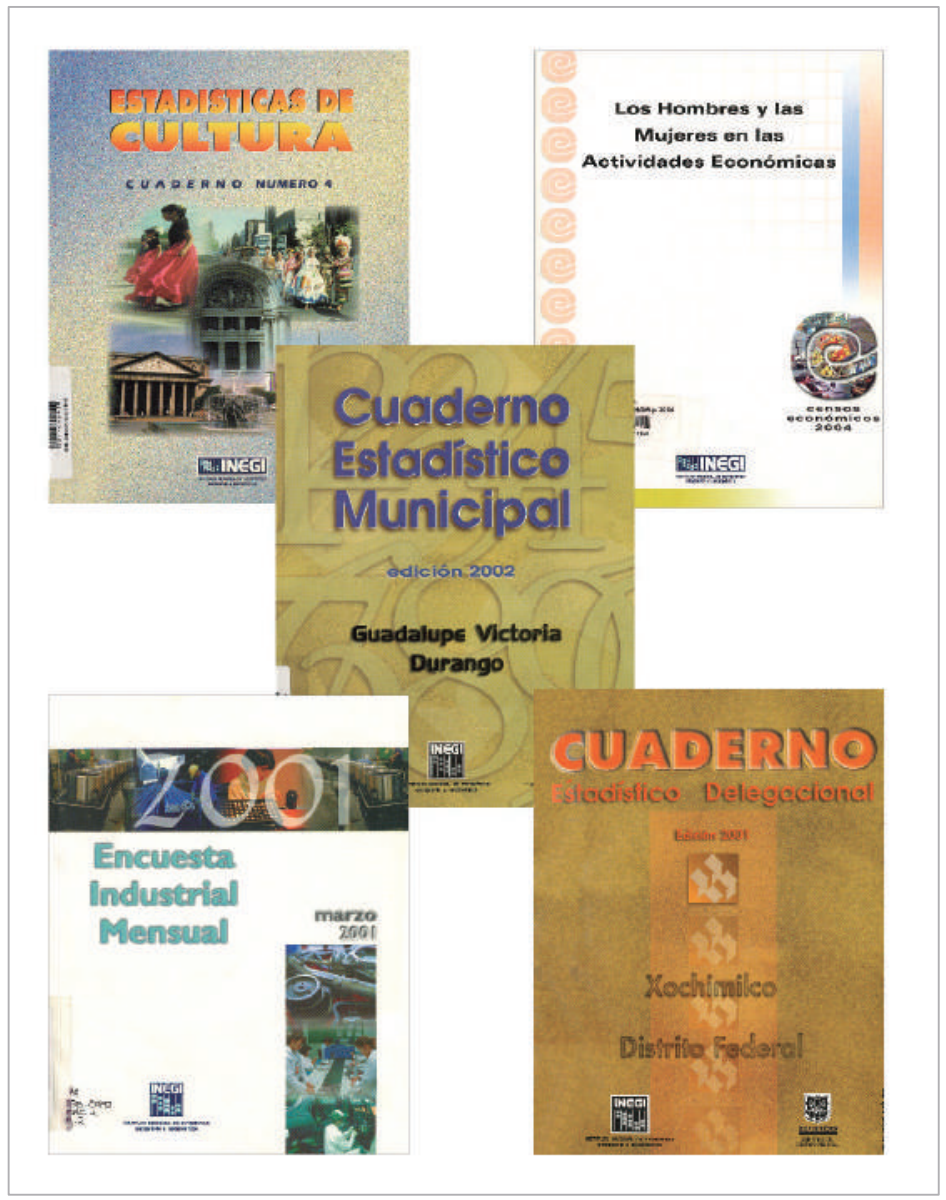

Imagen 4. Obras seriadas del INEGI, Mapoteca BNM.

para los formadores de recursos humanos, ya que permite conocer sus características sociales y su distribución en el país, junto con el promedio de sus ingresos- y el Atlas Ejidal por estado, ${ }^{25}$ que da cuenta de la localización geográfica y usos agrícolas.

\footnotetext{
${ }^{25}$ INEGI, Atlas ejidal del estado de Campeche. Encuesta Nacional Agropecuaria Ejidal 1988 (México: INEGI, 1991), acceso el 17 de mayo de 2019, https://www.inegi.org.mx/app/bus cador/default.html?q=Atlas+ejidal+del+estado+de+Campeche.
} 


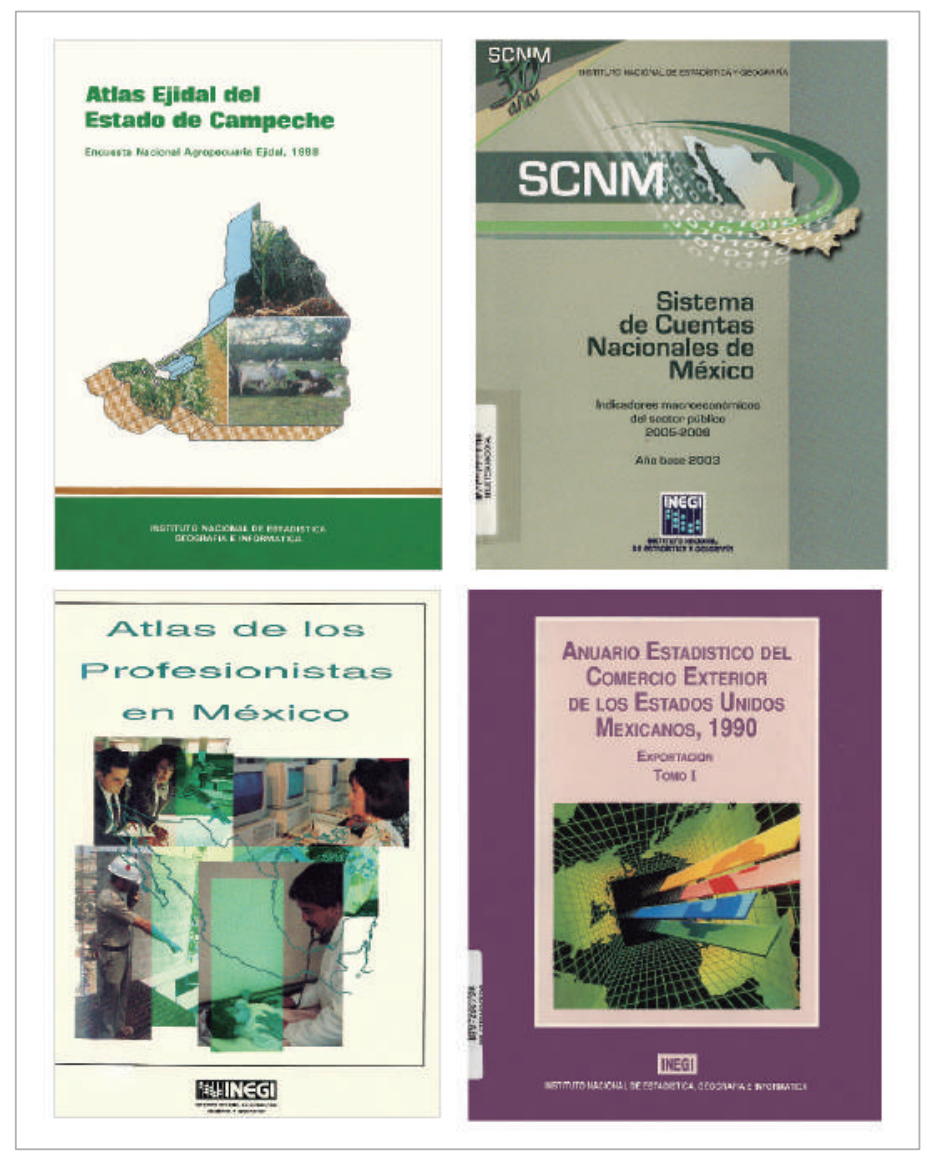

Imagen 5. Obras de gran formato del INEGI, Mapoteca BNM.

Otro rubro interesante del INEGI en la Mapoteca de la BNM son los boletines, catálogos y diccionarios (Imagen 6). Sobresale el Boletín de Estadísticas Vitales, que forma parte de la serie Boletín de Estadísticas Continuas Demográficas y Sociales, donde se difunden los datos más recientes sobre nacimientos, defunciones, matrimonios, divorcios, relaciones laborales, educación, salud y suicidios de la población mexicana. De carácter geográfico y científico hay varios, por ejemplo se cuenta con el Diccionario de datos fisiográficos, aplicable en urbanismo, y los aspectos militares y ambientales, entre otros. Por igual, el Diccionario de datos Geológicos, de gran impacto en la explotación minera, y 
la serie Estudio Hidrológico, que lleva el registro de las aguas subterráneas y superficiales de la nación. Además tenemos el Catálogo de herbario, ${ }^{26}$ de gran ayuda para conocer la vegetación del país y que se complementa con el Diccionario de datos de uso del suelo y vegetación.

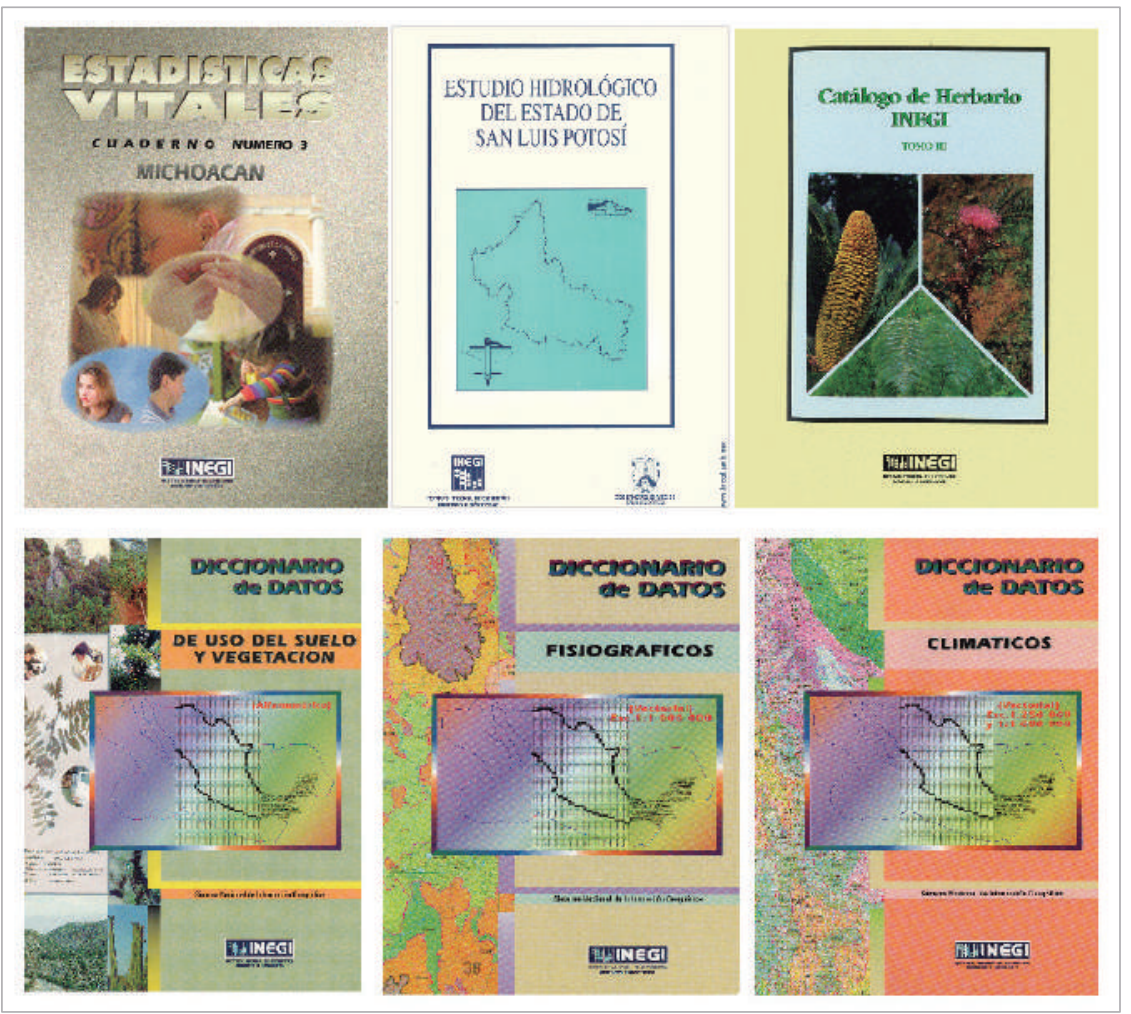

Imagen 6. Boletines, catálogos y diccionarios del INEGI, Mapoteca BNM.

La segunda colección más importante de la Mapoteca la representan las guías urbanas, turísticas y de carreteras, entre las cuales sobresale la Guía Rojii ${ }^{27}$

${ }^{26}$ INEGI, Catálogo de herbario INEGI II (México: INEGI, 1995), acceso el 17 de mayo de 2019, https://www.inegi.org.mx/app/biblioteca/ficha.html?upc=702825114480.

${ }^{27}$ Empresa editorial especializada en cartografía. Fue fundada en 1928 por Joaquín Palacios Roji Lara, cuya familia emigró en el siglo XIX de Bélgica a España, y luego a México. Su impulsor decidió publicar un mapa de la Ciudad de México en forma de libro, tomando como fuente de inspiración uno similar que encontró en Nueva York. A su muerte en 
(Imagen 7). De esa misma casa editorial hay una gran variedad de atlas de carreteras nacionales y países limítrofes como Estados Unidos de América, Guatemala y Belice. Los atlas turísticos de carreteras presentan planos y una lista alfabética de poblaciones con rutas de carreteras y caminos, tablas de distancia, hoteles y destinos turísticos, que registran la infraestructura vial del territorio mexicano, datos de gran utilidad para topógrafos e ingenieros, empresas constructoras e instituciones públicas.

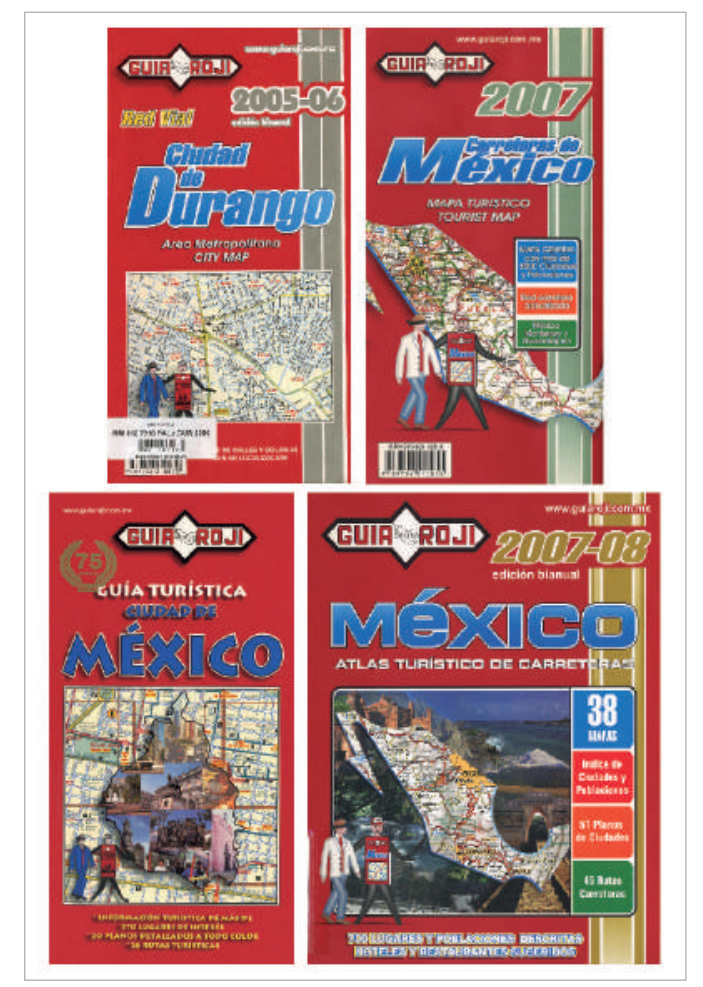

Imagen 7. Publicaciones de Guía Roji, Mapoteca BNM.

1962, sus hijos tomaron el liderazgo de la empresa y comenzaron a diversificar el negocio, integrando nuevas versiones de las principales ciudades de la república mexicana y el primer atlas de carreteras de México, con el apoyo de novedosas tecnologías como la fotografía aérea. En 1993 empezaron a utilizar DVD y CD-ROM, con otras aplicaciones o softwares a través de Internet. David Lida, "Hojear la Guía Roji es como leer la biografía de la Ciudad de México", MXCITY: Guía Insider, acceso el 17 de mayo de 2019, https://mxcity. mx/2017/02/la-peculiar-historia-de-roji-la-primera-guia-que-mapeo-la-ciudad/. 
Se tienen consignadas guías urbanas con planos de las principales ciudades de todo el país, actualizadas anualmente, de 1947 a 2016. Las guías de red vial y las guías turísticas de ciudades vienen acompañadas de un índice de localización de calles, colonias y avenidas, con elementos gráficos sobre sitios de interés y medios de transporte público; incluyen cálculos de distancias y tiempos de recorrido para orientar al público en general y en especial al turismo nacional o extranjero, para ayudarlo a llegar a su destino final. A estas guías se suman mapas murales de ciudades y estados, así como otras guías más completas que incluyen listas de los lugares relevantes de la zona metropolitana del valle de México, zonas postales, industriales, delegaciones, numeración de casas, rutas de tranvías, camiones y reglamentos de tránsito. El conocimiento de esta cartografía es fundamental para analizar los cambios en la nomenclatura de las calles, avenidas y sitios de interés, al igual que de los servicios públicos y las modificaciones a la traza urbana en una coyuntura de largo plazo.

En relación a las guías turísticas, las hay tanto de organismos oficiales como de casas comerciales. Aparte de las editadas por Guía Roji existen en la Mapoteca varias guías en inglés, francés e italiano sobre ciudades turísticas mexicanas (por ejemplo The Easy Guide to San Miguel de Allende, Guadalajara, Acapulco, etc.) y para el turismo de habla española hay guías para visitar ciudades extranjeras, como las publicadas por Editorial Trillas en su colección Guía de Ciudad Top 25.

En cuanto a la promoción oficial para conocer el territorio nacional se encuentran en el acervo las publicaciones de la Secretaría de Turismo y Transporte, al igual que de los gobiernos estatales y dependencias gubernamentales interesadas en su circulación, por la derrama económica que representa la actividad turística. A éstas se suman las mini guías culturales del INAH, las cuales contienen información sobre museos, zonas arqueológicas y monumentos coloniales, para difundir y dar a conocer el patrimonio de México. Esta folletería entregada a la BNM entre 1992 y 2011, con vocación educativa y de entretenimiento, incluye una monografía, un mapa del sitio y fotografías (Imagen 8).

La cartografía restante representa numéricamente un rubro significativo en el acervo, pero en su mayoría no está catalogada. Se tienen, sobre todo, mapas de dependencias institucionales y en menor medida de la iniciativa privada, que datan de finales del siglo XVIII, haciendo hincapié en el XIX y hasta el último tercio del XX. Estos documentos son útiles para comprender la geografía física y social de México, así como la evolución urbana de la capital nacional y las principales ciudades de la república. En el primer renglón sobresalen las car- 
tas esféricas levantadas por la Corona española durante el periodo virreinal, pasando por las de la Comisión Geográfica Exploradora para cada entidad federativa, hasta las publicadas en suplementos de revistas independientes (en 1938) y las cartas geológicas del Instituto de Geología de la UNAM (1968).

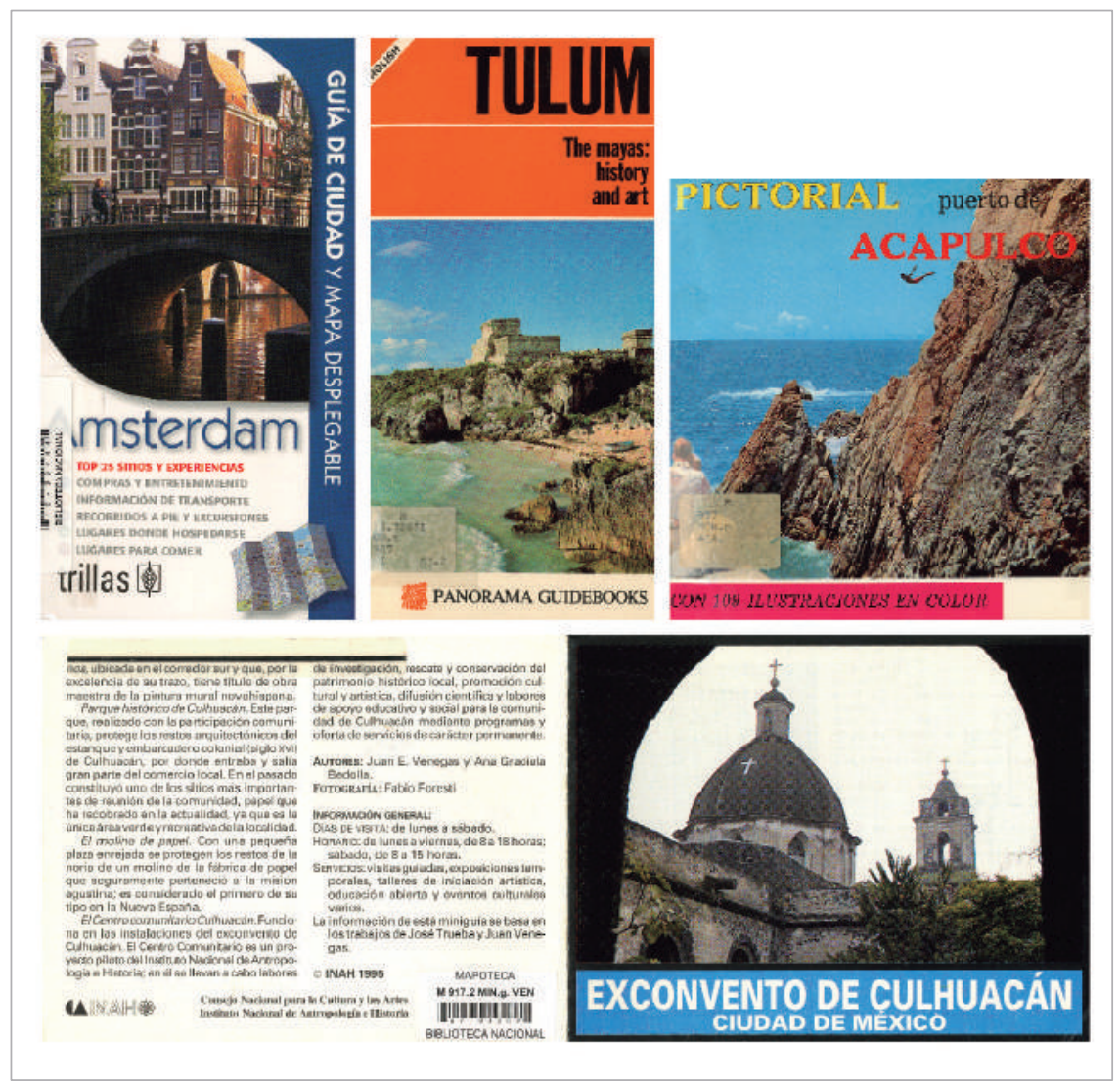

Imagen 8. Guías turísticas en inglés y español, Mapoteca BNM.

Por igual se localizan en este acervo mapas de la república mexicana que registran la división político-administrativa interna y sus límites con los países fronterizos, destacando la localización de los asentamientos humanos, tema de gran interés para la Secretaría de Fomento. A lo anterior se suman las cartas que señalan el recorrido de las comunicaciones terrestres como los ferrocarriles, las 
carreteras y el alumbrado marítimo de los puertos del país, ya sea la carta editada por la Secretaría de Comunicaciones y Obras Públicas, o bien la de los Talleres Gráficos de la Nación. Incluso se encuentran croquis de las vías exteriores y locales de lugares específicos (por ejemplo de San Juan Teotihuacán).

Se reseñan en mapas ciertos rubros de la producción económica nacional: la petrolera y la pesquera, de la Secretaría de Industria, Comercio y Trabajo. Hay cartas de aprovechamiento de aguas y suelos por estados o regiones de la Secretaría de Recursos Hidráulicos y, conjuntamente con la Secretaría de Agricultura, sobre la tenencia de la tierra; también pueden localizarse mapas escolares de la república mexicana, elaborados por imprentas comerciales para la enseñanza básica.

Asimismo, se incluyen planos urbanos de entidades federativas (Ciudad de México, Distrito Federal, Querétaro, Guadalajara y Mérida) que registran colonias o delegaciones, zonas postales y la nomenclatura de las calles, al igual que mapas turísticos de los estados que señalan medios de transporte y los lugares interesantes de cada región, levantados por la Secretaría de Fomento o la de Comunicaciones. Por último, está la cartografía que reseña servicios públicos en cuanto a la red telegráfica del país (1885), así como la limpia y el saneamiento de la Ciudad de México (1894) o el proyecto de higienización elaborado para el puerto de Manzanillo (1884).

Destaca en el acervo de la Mapoteca la cartografía histórica procedente del extranjero, sobre todo del continente americano. Se acuñan del Siglo de las Luces cartas de las posesiones españolas desde Chile y Río de la Plata, pasando por las Antillas, hasta África. En particular, mapas de Centroamérica (Guatemala, El Salvador y Panamá) y Sudamérica (Chile, Argentina y Uruguay) que muestran la orografía e hidrografía, la división política y administrativa de los departamentos, villas, pueblos, haciendas y aldeas, al igual que las comunicaciones. Sobresalen tesoros bibliográficos en buen estado de conservación, como es un mapa de El Salvador hecho a partir de 1892 y publicado en 1905 (MM917.284 BAR.n); y una joya para la historia geopolítica de Centroamérica y la disputa de los canales marítimos (ubicados en Panamá, Nicaragua y Tehuantepec) por parte de las potencias extranjeras, un plano publicado en Londres, en 1853, por John Baily (M912.728 BAL.m) (Imagen 9). Despunta aquí la colección de la National Geographic Society y de su revista para conocer, en el siglo XX, el territorio de Estados Unidos de América, desde el sudoeste hasta Alaska. 

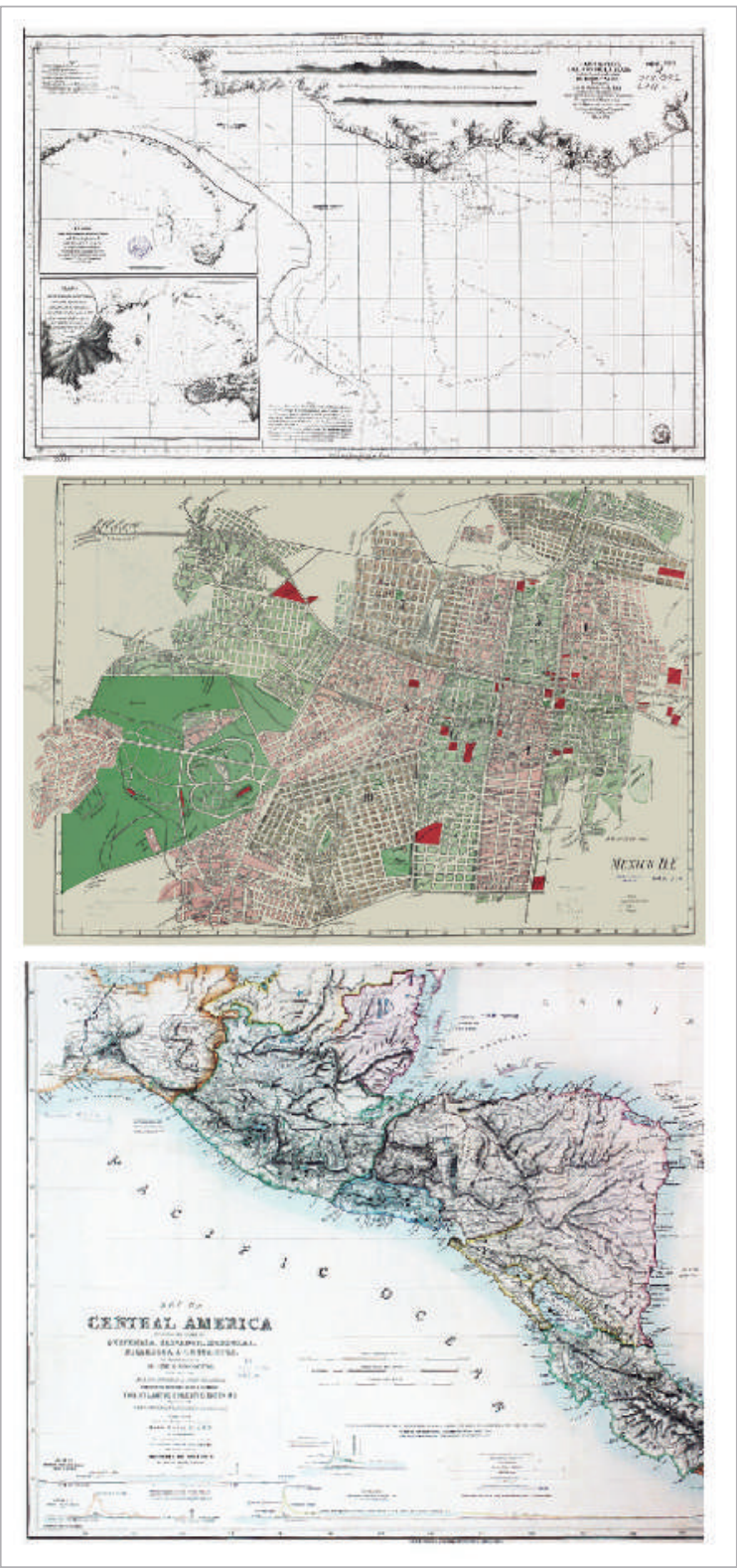

Imagen 9. Cartografía histórica en la Mapoteca de la BNM. 
La Mapoteca tiene una sección de revistas, catálogos y atlas en la que resalta el Boletín de la Sociedad de Geografía y Estadística de la República Mexicana, compuesto por 90 volúmenes que abarcan del año 1850 a 1972. Si bien la colección está incompleta, ya que circuló de 1839 a 1999, es importante su repertorio porque fue impulsado por la primera sociedad científica y cultural de América, se constituyó como uno de los primeros órganos de difusión de la ciencia mexicana y fue el primero de circulación internacional. Para México, fue sin duda alguna la primera revista de geografía del país, que publicaba artículos sobre la vida social y sus vínculos con el territorio nacional, mediante una comprensión amplia de esta disciplina en su ámbito multidisciplinario. ${ }^{28}$

En el acervo también son valiosos testigos los catálogos de cartografía histórica de estados, países y continentes, por ejemplo los de monumentos arquitectónicos. Semejantes a ellos en materia de contenidos se encuentran los atlas históricos referentes a las viejas civilizaciones, a las exploraciones científicas y al patrimonio perdido en el mar, así como a la historia del descubrimiento de América y el registro de su población. Y así, un sinfín de obras de gran calidad editorial, no sólo de México sino de otros países.

Son interesantes los saberes enciclopédicos que se encuentran en los atlas sobre el universo y el planeta tierra, los de geografía e historia universal elaborados por imprentas extranjeras y editados en París (1877) y Londres (1857), como los de la república mexicana donde aparecen representadas las primeras cartas para la enseñanza escolar (García Cubas, 1874).

También encontramos en el acervo atlas contemporáneos universales (publicados por Reader's Digest), continentales (por ejemplo de Europa), de países (Argentina, Brasil, Canadá, Chile, España, Estados Unidos de América y México) y de los estados y ciudades de nuestro país (Chihuahua, Baja California, Ciudad de México, Distrito Federal, Estado de México, Monterrey y Tabasco), a los que se suman una variedad de tópicos sobre infraestructura cultural, migración, de rutas postales y marítimas, de cambios climáticos, agua, salud, riego, actividades económicas, seguridad, violencia, educación y recursos hídricos (Imagen 10).

\footnotetext{
${ }^{28}$ Los tópicos tratados en este boletín se relacionaban con la biología, botánica, geología, matemáticas, física, agrimensura, geodesia, literatura, historia, filología, meteorología, sismología, radiación solar, arqueología, antropología y psicología, entre otros. Luz Fernanda Azuela Bernal, "La Sociedad Mexicana de Geografía y Estadística, la organización de la ciencia, la institucionalización de la geografía y la construcción del país en el siglo XIX", Investigaciones Geográficas 52 (diciembre de 2003): 158-159.
} 


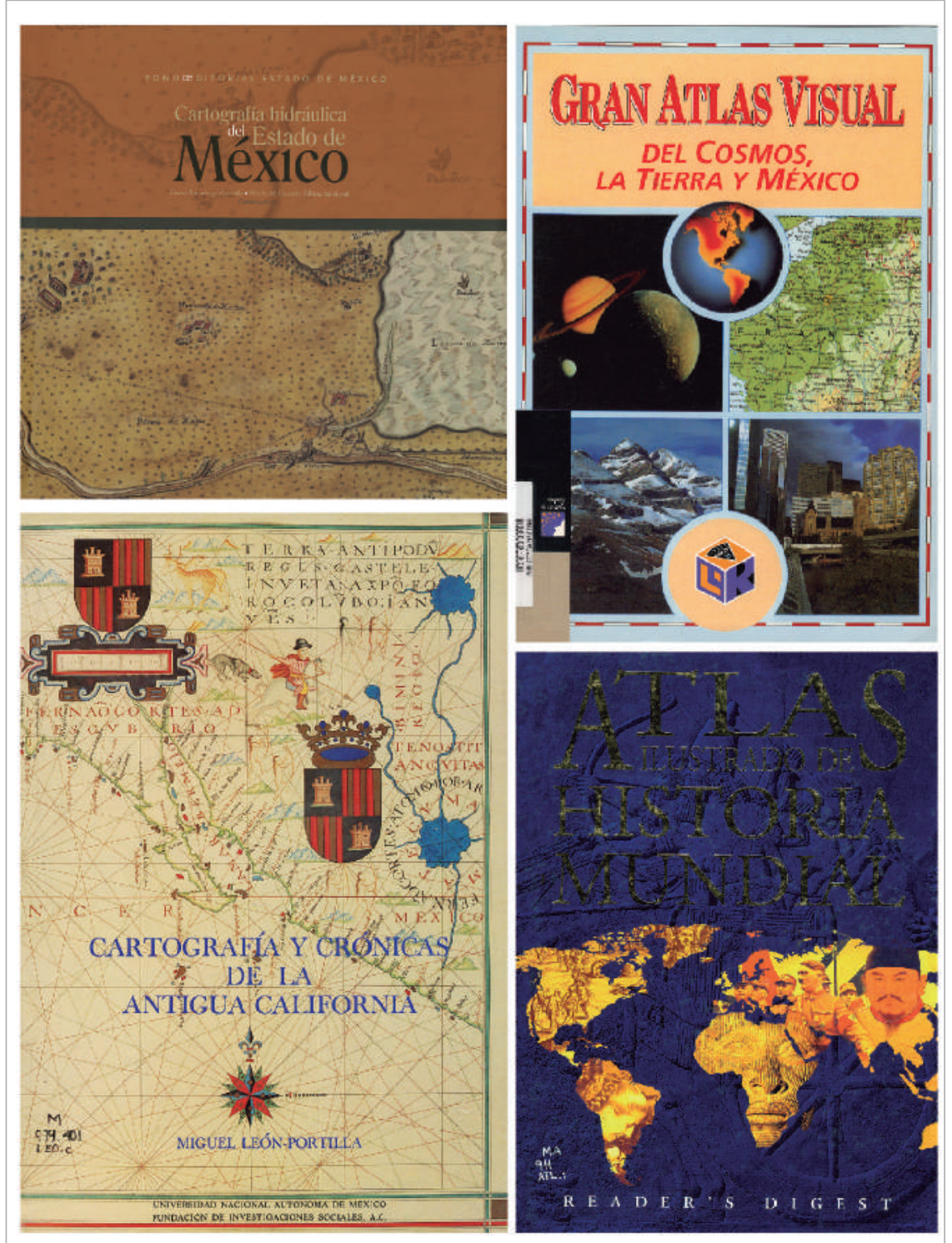

Imagen 10. Atlas y catálogos en la Mapoteca de la BNM. 


\section{Conclusiones}

Como se ha visto, la Mapoteca de la Biblioteca Nacional de México conserva colecciones de gran importancia como la del Instituto Nacional de Estadística, Geografía e Informática, el órgano descentralizado que genera la mayor información estadística del país, para que los mexicanos podamos conocerlo y proyectarlo mejor. Gracias a la intensa actividad de Guía Roji también se ha podido conocer el crecimiento urbano de las principales ciudades mexicanas y la expansión de carreteras del país durante el siglo XX aunque, después de 90 años de labores, esta empresa se despide del mercado comercial debido a la reciente competencia de aplicaciones tecnológicas como Google Maps y Waze. Frente a esta situación, queda bajo el resguardo de la BNM la memoria y la constancia de su gran trabajo editorial.

La Mapoteca de la BNM tiene una enorme labor en términos de catalogación y conservación, e incluso es menester completar algunas colecciones importantes. Respecto a la primera disciplina, falta por describir y registrar revistas extranjeras, las primeras guías nacionales, la cartografía actual del INEGI y la histórica que se resguarda de México y del mundo y, sin lugar a dudas, de otras fuentes valiosas que serán dadas a conocer conforme avance la descripción bibliográfica de su acervo.

\section{Referencias}

Azuela Bernal, Luz Fernanda. "La Sociedad Mexicana de Geografía y Estadística, la organización de la ciencia, la institucionalización de la geografía y la construcción del país en el siglo XIX". Investigaciones Geográficas 52 (diciembre de 2003): 153-166.

Biblioteca Nacional de México, Universidad Nacional Autónoma de México. "Nautilo: Catálogo de la Biblioteca y Hemeroteca Nacional". Acceso el 17 de mayo de 2019. http://catalogo.iib.unam.mx/F/-/?func=find-b-0\&local_ base $=$ BNM.

Carrasco Puente, Rafael. Historia de la Biblioteca Nacional de México, con texto en inglés traducido por Erwin K. Mapes. México: Secretaría de Relaciones Exteriores, Departamento de Información para el Extranjero, 1948.

Casillas, Gabriel. "Reconocimiento INEGI 2015". El Financiero (29 de septiembre de 2015). Acceso el 17 de mayo de 2019. https://www.elfinanciero.com. mx/opinion/gabriel-casillas/reconocimiento-inegi-2015. 
Cázares Aguilar, Rocío. Entrevista a Ludmilla Valadez Valderrábano el 10 de octubre de 2018.

Escamilla, Gloria. "Consideraciones sobre la organización de los materiales cartográficos". Boletín del Instituto de Investigaciones Bibliográficas, núms. 14-15 (1977-1978): 583-592.

Hermosín Miranda, Rocío. "Características de los distintos soportes sobre los que se reproducen planos y esferas". Revista ph 77 (febrero de 2011): 47-53.

Iguíniz, Juan B. "La Biblioteca Nacional de México". Revista de Historia de América 8 (abril de 1940): 57-86.

Instituto Nacional de Estadística Geografía e Informática (INEGI). Atlas de los profesionistas en México. México: Instituto Nacional de Estadística Geografía e Informática, 1995. Acceso el 17 de mayo de 2019. https://www.inegi.org. $\mathrm{mx} / \mathrm{app} /$ biblioteca/ficha.html?upc=702825460310.

Instituto Nacional de Estadística Geografía e Informática. Atlas ejidal del estado de Campeche. Encuesta Nacional Agropecuaria Ejidal 1988. México: Instituto Nacional de Estadística Geografía e Informática, 1991. Acceso el 17 de mayo de 2019. https://www.inegi.org.mx/app/buscador/default.html?$q=$ Atlas+ejidal+del+estado+de+Campeche.

Instituto Nacional de Estadística Geografía e Informática. Catálogo de herbario INEGI II. México: Instituto Nacional de Estadística Geografía e Informática, 1995. Acceso el 17 de mayo de 2019. https://www.inegi.org.mx/app/biblioteca/ficha.html?upc $=702825114480$.

Instituto Nacional de Estadística Geografía e Informática. Coyoacán: cuaderno de información básica delegacional. México: Instituto Nacional de Estadística Geografía e Informática, 1989. Acceso el 17 de mayo de 2019. https:// www.inegi.org.mx/app/biblioteca/ficha.html?upc=702825004885.

Instituto Nacional de Estadística Geografía e Informática. Encuesta industrial mensual marzo 2001. México: Instituto Nacional de Estadística Geografía e Informática, 2006. Acceso el 17 de mayo de 2019. https://www.inegi.org. $\mathrm{mx}$ /programas/eim/1994/.

Instituto Nacional de Estadística Geografía e Informática. Estadísticas de cultura (4). México: Instituto Nacional de Estadística Geografía e Informática, 2000. Acceso el 17 de mayo de 2019. https://www.inegi.org.mx/app/biblioteca/ficha.html?upc=702825465193.

Instituto Nacional de Estadística Geografía e Informática. Los hombres y las mujeres en las actividades económicas: censos económicos 2009. México: Instituto Nacional de Estadística Geografía e Informática, 2011. 
Instituto Nacional de Estadística Geografía e Informática. "Institución con historia". México: Instituto Nacional de Estadística Geografía e Informática. Acceso el 17 de mayo de 2019. https://www.inegi.org.mx/inegi/quienes_ somos.html.

Instituto Nacional de Estadística Geografía e Informática. "Instituto autónomo, de frente a los nuevos retos". México: Instituto Nacional de Estadística Geografía e Informática. Acceso el 17 de mayo de 2019. https://www. inegi.org.mx/inegi/quienes_somos.html.

Instituto Nacional de Estadística Geografía e Informática. Perfil sociodemográfico de Tamaulipas. XII Censo General de Población y Vivienda 2000. México: Instituto Nacional de Estadística Geografía e Informática, 2002.

Lida, David. "Hojear la Guía Roji es como leer la biografía de la Ciudad de México". MXCITY: Guía Insider. Acceso el 17 de mayo de 2019. https://mxcity. mx/2017/02/la-peculiar-historia-de-roji-la-primera-guia-que-mapeo-laciudad/.

Ligas a cartografía actual del INEGI: http://internet.contenidos.inegi.org.mx/contenidos/Productos/prod_serv/contenidos/espanol/bvinegi/productos/ geografia/tematicas/Efec_may_oct_hist/702825680329.pdf.

http://internet.contenidos.inegi.org.mx/contenidos/Productos/prod_ serv/contenidos/espanol/bvinegi/productos/geografia/tematicas/Hidro_ super_hist/1_250_000/702825684013.pdf.

http://internet.contenidos.inegi.org.mx/contenidos/Productos/prod_ serv/contenidos/espanol/bvinegi/productos/geografia/imagen_cartogra fica/1_50_000/702825203351_geo.pdf.

https://www.inegi.org.mx/app/biblioteca/ficha.html?upc=7028252103 $28 \mathrm{M}$.

Serrano, Aurora y Ludmilla Valadez. "Los servicios al público en las salas de bibliografía y mapoteca de la Biblioteca Nacional de México". En Hacia un servicio bibliotecario nacional: memorias de la VII Semana de Bibliotecología, del 8 al 10 de febrero de 1984, 99-117. Guadalajara: Universidad Autónoma de Guadalajara, División de Educación Continua, Dirección de Bibliotecas Médicas, Facultad de Filosofía y Letras, Escuela de Bibliotecología, 1984.

Subcomité de Normalización para la Preservación de Acervos Documentales del Comité Técnico Nacional de Documentación, "NMX-R-100-SCFI-2018, Acervos Documentales-Lineamientos para su preservación". Declaratoria de vigencia en proceso de publicación. 
Vigil, José María. Catálogos de la Biblioteca Nacional de México; novena división, historia y ciencias auxiliares. México: Secretaría de Fomento, 1893.

Villalobos Acosta, César. "Arqueología mexicana en guías de turistas: educación y pasatiempo". Anales de Antropología 48, núm. 2 (julio de 2014): 41-73.

Weessies, Kathleen. "Care of Rare Map Collections in the Twenty-First Century". Journal of Map \& Geography Libraries 10, núm. 2 (julio de 2014): 204235. $* b g$ 